\title{
OS SIGNOS DO CONSUMO E SUAS MÚLTIPLAS EXPRESSÕES
}

\author{
Clotilde Perez e Eneus Trindade
}

O primeiro número da edição da Revista Eletrônica Signos do Consumo trouxe, na sua apresentação e no conjunto de seus artigos e resenhas, a discussão que constata a necessidade da abertura de espaços de reflexão acerca dos signos do consumo contemporâneo, tendo em vista a transmutação dos sentidos do mundo tido como "real", em um mundo sígnico, cuja dimensão semiósférica opera a mediação do único meio de acesso a biosfera e a tecnosfera, como argumentaria luri Lótman ao discutir a problemática da tipologia das culturas. Os signos do consumo conquistaram muitos espaços em novas dimensões.

Essa conquista dos espaços sígnicos é indicadora de uma busca pelo conhecimento que nos permite a conformação de um campo científico específico das Ciências da Comunicação, hoje em dia cada vez mais valorizado, que se refere à comunicabilidade como elemento estabelecedor de vínculos de sentidos, especificamente os vínculos dados entre os signosmercadoria (tangíveis e intangíveis) e o cotidiano vivido pelos homens.

É justamente nesse hiato que a Revista Signos do Consumo busca seu espaço e oferece sua contribuição para a legitimação deste campo específico dos estudos comunicacionais, o qual se constitui na dinâmica da produção de sentido da comunicação para o mercado em suas interfaces sociais. Entendendo-se também que tal produção de sentido é reflexo do mundo vivido e, ao mesmo tempo, é reguladora das dinâmicas sociais que institui e destitui na vida social, conforme a lógica do poder simbólico tratada por Pierre Bourdieu.

A natureza diversa dos fenômenos sígnicos e suas respectivas produções de sentidos nos mostram a necessidade de um olhar teórico sobre os objetos empíricos que reconheça essa mutiplicidade de expressões que demandam uma combinaçãointerdisciplinar da construção do conhecimento sobre tais ocorrências comunicacionais.

Não é por acaso que os estudiosos da linguagem, em suas várias vertentes, sempre buscaram considerar a expressividade sígnica como elemento fundamental de suas teorizações, como meio de acesso aos sentidos e às significações, pois as formas informam conteúdos e direcionam padrões de percepção que constituem a práxis social de uma dada cultura.

Aprendemos nos estudos introdutórios sobre a linguagem que, Louis T. Hjelmslev a partir de sua elaboração teórica sobre a obra de Saussure, que o signo ganha as dimensões das substâncias e das formas do conteúdo e da expressão. Já Charles Sanders Peirce, na 
formulação de sua teoria semiótica, mostra-nos que o signo assume várias possibilidades de significação, representação e interpretação em relação a si mesmo, frente ao objeto que representa, bem como aos interpretantes que têm a possibilidade de gerar, chegando à abstração máxima da semiose ilimitada. Por fim, na esteira de autores que refletem as bases filosóficas dos estudos da linguagem, em Mikahil Bakhtin, percebemos que o signo traz consigo o conflito, pela sua natureza dialógica e polifônica, que se traduz na heterogeneidade constitutiva de todo e qualquer tecido discursivo.

Nesse sentido, os signos do consumo não fogem dessas especificações e trazem consigo para a problemática do

entendimento humano sobre os fenômenos do mundo, toda a complexidade de suas múltiplas manifestações e respectivas implicações para a vida social. A partir do exposto, podemos considerar que o conjunto dos artigos e resenhas deste segundo número do primeiro ano de circulação da Revista Signos do Consumo, apresenta alguns dos aspectos destas variadas expressividades.

Para inaugurar esta edição, discutindo essas múltiplas manifestações do universo sígnico do consumo, trouxemos o artigo Marca turística y movie maps. Identidad, cine y publicidad como producto de consumo, dos pesquisadores espanhóis da Universidade de Murcia, Prof. Dr. Pedro A. Hellín Ortuño e o doutorando Salvador Martinez Puche, que abordam o fenômeno da oferta de destinos turísticos a partir de lugares representados em filmes. A mediação sígnica do cinema de ficção sobredetermina a produção da oferta turística, assim como a publicidade que a divulga, demarcando um fenômeno recente do consumo que tem ganhado vários adeptos no mundo. A dinâmica complexa entre gêneros discursivos (cinema, publicidade, discurso sobre o turismo) mostra a trama sígnica que tal objeto se insere.

Na seqüência o pesquisador, Prof. Dr. Vander Casaqui, da Escola Superior de Propaganda e Marketing de São Paulo, discute a Publicidade Pós-moderna: processos de representação e referencialidade, trazendo a perspectiva de discussão epistemológica sobre a relação signoobjeto, inserida no contexto do universo discursivo da publicidade e sua mediação para o consumo.

O terceiro artigo Agência de propaganda: casa de Orates ou templo do Oráculo, realizado pelo Prof. Dr. Goiamérico Felício Carneiro dos Santos, da Universidade Federal de Goiás, traz discussões pertinentes ao cotidiano do profissional da área publicitária, permitindo-nos a reflexão sobre o lado operacional do universo de produção dos signos do consumo pela atividade publicitária, considerando as problemáticas que constitui o drama vivido por esses profissionais na contemporaneidade para manterem-se ativos na profissão, mostrando os desafios e os dilemas éticos, morais da vida profissional e que ao mesmo tempo tem que 
difundir possibilidades de completude por meio do estímulo ao consumo de bens e serviços de seus anunciantes/clientes.

A multiplicidade de expressões sígnicas se confirma novamente no quarto artigo da revista, pois os signos do consumo da comunicação política ganham aqui seu espaço de discussão a partir do texto Breve história dos slogans políticos nas eleições do Brasil republicano, escrito pelo Prof. Dr. Adolpho Queiroz e pelo mestrando Carlos Manhanelli, ambos da Universidade Metodista de São Paulo -São Bernardo do Campo. Os autores operam uma análise de conteúdo junto ao conjunto expressivo de slogans políticos, mostrando o papel dessa mediação sígnica na definição de processos eleitorais, o que em parte cria a conexão entre consumo e eleição, já que as dimensões da campanha determinam os custos dos votos conquistados.

Em seguida, mantendo a lógica da multiplicidade das expressividades dos signos, a pesquisadora Dra. Gisele Gubernikoff do Museu Paulista da Universidade São Paulo, apresenta o artigo Cinema e publicidade: dividindo a mesma tela, cuja discussão mostra o hibridismo do cinema como mídia de consumo, uma vez que suas histórias tornam-se referencias para adoção das práticas de consumo, sobretudo no universo feminino, foco do texto em questão, o que possibilita o entrecruzamento do cinema com a publicidade e as questões de representação do gênero feminino.

As questões de gênero e consumo também continuam presentes nesta edição, na discussão do Prof. Dr. Wilton Garcia da Universidade Braz Cubas -SP, que aborda especificamente o tema Consumo e diversidade cultural/sexual: investigações interdisciplinares, trazendo à tona as discussões sobre o consumo e a representação nas comunicações para o mercado junto ao público de gays, lésbicas, bissexuais e transexuais.

Outro aspecto da mediação sígnica destacado nesta edição é o caráter regulador do signo publicitário, ou seja, o signo no seu papel político na regulação dos processos de consumo, como nos faz perceber o artigo É possível se falar em política no consumo como recurso na promoção de marcas juvenis? Considerações a partir da campanha: Oi, bloqueio não!, de Mônica Machado, Professora Assistente da Escola de Comunicação (ECO) da Universidade Federal do Rio de Janeiro (UFRJ) e Doutoranda do Programa de Pós-Graduação da ECO/UFRJ.

E o último artigo desta edição, de Érica de Holanda, Mestranda em Comunicação Social da Universidade do Estado do Rio de Janeiro (UERJ), trata da transformação do suporte livro impresso para e-book, considerando suas implicações na leitura e, sobretudo, no consumo de livros, a partir desta nova expressividade do signo-objeto livro. 
Além dos artigos, esta edição conta também com duas resenhas. A primeira delas realizada pela Mestranda do PPGCOM da ECA/USP, Janiene dos Santos e Silva, discute a obra organizada pelo pesquisador italiano da Domus e do Politécnico de Milão, Francesco Morace, intitulada Consumo autoral: as gerações como empresas criativas, editado pela Cia. das Letras em 2009, cuja discussão traz o foco para o consumidor como local privilegiado para a deteç̧ão de tendências de consumo entre gerações de indivíduos dos centros urbanos contemporâneos. $O$ livro discute o processo de identificação de tendências como algo verificável nos cotidianos dos ambientes de consumo a partir de observações flutuantes e registros etnográficos que certamente nos obriga a pensar o lugar e o olhar sobre o receptor-consumidor nas dinâmicas comunicacionais atuais, uma vez que todos querem deixar sua "marca" e protagonizar as múltiplas possibilidades de manifestação no mundo.

A segunda resenha, realizada pela Mestranda do Programa de Estudos Pós-Graduados em Administração da PUC-SP Luciana Balensifer Pereira, nos traz um instigante roteiro de leitura acerca da obra de Edmour Saiani, Loja viva: revolução no pequeno varejo brasileiro, editado pelo SENAC Rio de Janeiro, em 2004. A obra em pauta, apesar de não ser tão recente, permite a reflexão sobre aspectos fundamentais do consumo das classes populares, demarcando a importância dessa reflexão negligenciada até a bem pouco tempo, tanto pelo mercado quanto pela academia.

E para darmos desfecho a esta apresentação, gostaríamos de manifestar, nesse primeiro ano da Revista Signos do Consumo, os nossos agradecimentos a todos que nos apoiaram na realização deste projeto. A revista agora se consolida buscando o seu permanente aperfeiçoamento, trazendo desafios reflexivos a cada número.

Agradecemos ao Chefe do Departamento de Relações Públicas Propaganda e Turismo da ECA/USP, Prof. Dr, Victor Aquino, pelo apoio incondicional ao projeto desta revista. A todos os colegas da ECA e da USP, de universidades do Brasil e do exterior que aceitaram fazer parte do Conselho Científico da revista. E, principalmente, à equipe de Secretaria e produção da Revista, composta por Fernanda Neves Leite, Victor Farah Brahim, Bruno Pompeu Marques Filho, Fábio Alvim e Lílian Nosralla, à ARCO-Associação de Apoio à Comunicação e Artes, representada pelo Prof. Dr. Arlindo Ornelas Figueira Neto, e aos Coordenadores dos Cursos de Especialização do Departamento de Relações, Públicas, Propaganda e Turismo da ECA em: Pesquisa de Mercado em Comunicações; Marketing Político e Propaganda Eleitoral; Publicidade \& Mercado; Comunicação em Marketing, que patrocinaram a produção dos dois números deste ano.

Além destes, cabe ainda ressaltar que a coordenação da Revista Signos do Consumo, realizada na gestão integrada entre o GIELP -Grupo/Núcleo Interdisciplinar de Estudos Da Linguagem 
Publicitária CNPq/ECA/USP e o GESC3 -Grupo de Estudos em Semiótica, Comunicação, Cultura e Consumo CNPq/USP e PUCSP, comprometeu-se com a qualidade de seu corpo de avaliadores _ o que, certamente, garantiu o êxito dos propósitos deste novo espaço de divulgação científica, e que merecem os nossos mais respeitosos reconhecimentos.

Dessa maneira, agradecemos nominalmente aos avaliadores deste primeiro ano: Prof. Dr. Adolpho Queiroz (UMESP), Prof. Dr. André Lemos (UFBA), Prof. Dr. Dennis de Oliveira (USP), Profa. Dra. Eliana Menezes de Melo (UBC), Prof. Dr. Eduardo Refkalefsky (UFRJ), Profa. Dra. Isaltina Gomes (UFPE), Prof. Dr. João Anzanello Carrascoza (ESPM/USP), Prof. Dr. Paulo Cunha (UFPE), Prof. Dr. Paulo Nassar de Oliveira (USP), Profa. Dra. Sandra Maria Ribeiro de Souza (USP), Prof. Dr. Sérgio Bairon (USP), Prof. Dr. Vander Casaqui (ESPM), Profa. Dra. Vera Crevin (Mackenzie) e Prof. Dr. Wilton Garcia (UBC).

Desejamos a todos uma boa leitura. 